\title{
A Review on Selective Laser Sintering: A Rapid Prototyping Technology
}

\author{
K.R. Bakshi, A. V. Mulay \\ (Department of Production and Industrial Engineering, College Of Engineering, Pune, India)
}

\begin{abstract}
The components which were assumed to be very difficult to produce or manufacture some years ago can now be made easily using additive manufacturing technology. Additive Manufacturing offers many advantages in the production of parts, presenting freedom for design with the ability to manufacture single or multiple components from a wide range of materials. Different techniques of additive manufacturing are entailed. Selective Laser Sintering as an additive manufacturing technology fuses or sinters the successive powder layers to produce the part. The variety of materials that the process can adopt are discussed. The principle of the process, its elements, characteristics and applications are discussed in detail. The process is also having some disadvantages. This technology requires Laser as an energy source, powder feeder, Closed Chamber for controlled environment. The characteristics of the produced parts with important process parameters are mentioned. The paper provides information of additive manufacturing along with the Selective Laser Sintering process introduction and identification of its different parameters that influence the process.
\end{abstract}

Keywords: Selective laser Sintering, Rapid prototyping, Scan speed, powder deposition, grains

\section{INTRODUCTION}

In earlier decades, emphasize was given to the traditional ways of manufacturing any product. But as the technology evolved day by day, a new approach is developed in the manufacturing industry sector where prototyping became one of the important stage in the overall process of designing any part. Additive manufacturing technology is the foremost technology used now a days to make the prototypes of the designed parts [1]. Variety of materials can be processed by using different technologies such as stereo lithography, SLS, Fused deposition method etc. Unlike a subtractive process rapid prototyping is in additive process where the layers of material are added over each other to produce the final part which simplifies the process and enables it to be automated very easily [2]. In AM, at first, cad model is created using any modelling software, then, that model is sliced into no of layers (2D). This layered file is called as STL (Standard Tessellated Language) file. This file acts as an input file for the rapid prototyping systems and according to this file, layers get built over each other [3].

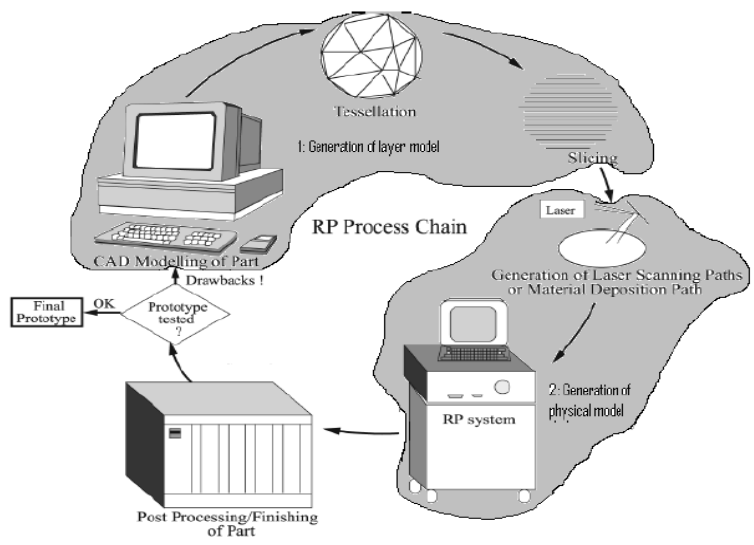

Fig.1. RP process chain [3].

Selective Laser Sintering (SLS, registered trademark by DTM of Austin, Texas, USA) is a process that was patented in 1989 by Carl Deckard. Selective laser sintering was first done mainly on polymers and nylon to 
IOSR Journal of Mechanical \& Civil Engineering (IOSRJMCE)

e-ISSN: 2278-1684,p-ISSN: 2320-334X

PP 53-57

www.iosrjournals.org

create prototypes. Gradually it was expanded to include metals and alloys to manufacture functional prototypes and develop rapid tooling. Due to the varied material capabilities, Selective Laser Sintering (SLS) process now stands as an alternative to conventional manufacturing techniques. Because of the wide range of materials it can process, SLS is superior to other Rapid Manufacturing techniques.

\section{LITERATURE REVIEW}

Sanjeev Kumar [1] presented an article on "Selective laser sintering: a qualitative and objective approach" In this article, a total review of SLS process is discussed. Different materials for SLS process, binding mechanisms, preprocessing, experimental parameters and post processing is discussed in detail. Sharanjit Singh [2] presented a paper on "Investigation of Dimensional Accuracy/Mechanical Properties of Part Produced by Selective Laser Sintering". In this paper, the experimental investigation of the SLS is carried out. A 25-100 Watt $\mathrm{CO}_{2}$ laser is used with polyamide powder as a raw material. After testing, dimensional and mechanical properties are checked. Despa [3] presented a paper on "study of selective laser sintering -A qualitative and objective approach" In this paper, a synthetic review of the process of Selective Laser Sintering is made. A deep review is taken on all the aspects of the SLS process that is from materials to the post processing of parts. Various material are listed that can be used for SLS process. Bonding mechanism is discussed in detail and a view on thermal modelling of amorphous polymers is presented. Singh and. Chauhan [4] presented a paper on, "An overview of rapid prototyping technology". This paper provides an overview of rapid prototyping technology in brief and emphasizes on their ability to shorten the product design and development process. Classification of rapid prototyping processes and details of few important processes is given. An attempt has been made to include some important factors to be considered for proper utilization of potentials of rapid prototyping processes. Pandey [5] presented report on "Rapid prototyping technologies, applications and Part deposition planning". This paper provides an overview of RP technology in brief and emphasizes on their ability to shorten the product design and development process. Classification of RP processes and details of few important processes is given. The description of various stages of data preparation and model building has been presented. Tang [7] presented a paper on "Direct laser sintering of copper based alloy for creating 3 Dimensional metal parts". He discussed the importance of direct laser sintering. Special copper based alloy is used for rapid prototyping process. Produced parts are tested for different tests such as surface roughness, mechanical properties to study the variation due to process parameters. Paper on "Homogeneity aspects in selective laser sintering" is presented by S. Kolosov [8]. In this, a measure of powder layer homogeneity is proposed. Different layer deposition techniques were checked for layer quality and thickness. Techniques used for deposition were 1. Classical deposition 2. Pressure-gradient deposition 3. Ultrasound powder compaction 4. Spread method etc. SEM images of all are studied. Powder layer quality is measured by means of heterogeneity coefficient and results are discussed [8]. Murli [9] presented paper on "Direct Selective Laser Sintering of irongraphite powder mixture" In which they presented a work on laser sintering of powder mixture of iron and graphite (99.22 and $0.78 \%$ respectively) was carried out using a pulsed Nd-Yag Laser. In this investigation, they attempted to produce and study an innovative metallic microstructure from a mixture of iron and graphite powder by laser sintering by employing a pulsed Nd-Yag Laser. They faced some problems. The products developed with these material suffer from low a research work on rapid prototyping technology with laser additive manufacture of wire based alloy Ti-6Al mechanical strength and durability. They can hardly be employed for functional prototypes of engineering components. In some cases, post process operations are necessary for achieving full density. Miranda et al. [10] presented a paper "Rapid prototyping with high power fibre laser" in which they presented $-4 \mathrm{~V}$ with an $8 \mathrm{~kW}$ fibre laser for the production of component with cylindrical geometry. High power fibre lasers have considerable advantages in rapid prototyping, due to flexibility in beam position and manipulation. Additionally these lasers have high power with low beam divergence, high efficiency, low maintenance cost and small implementation space.

\section{CLASSIFICATION OF ADDITIVE MANUFACTURING PROCESSES}

Additive manufacturing processes are broadly classified in various ways that is depending on the raw material, form of raw material, principles used in technique or the nature of the material used. According to the form of raw materials. SLA is used for Liquid resins, SLS is used for powdered form of materials (metals, ceramics, polymers), FDM (fused deposition method) is used for solid materials and LOM (laminated object manufacturing) is used for sheets of materials. The classification is shown in following Fig 2. 


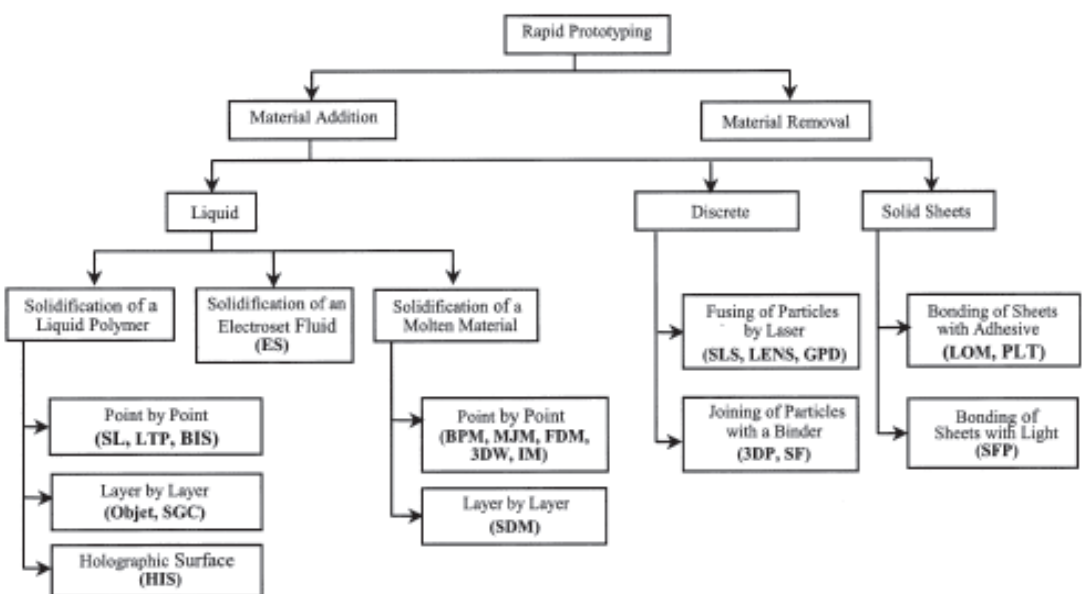

Figure 2. Classification of additive manufacturing processes [4].

\section{WORKING OF SELECTIVE LASER SINTERING PROCESS}

The term "sintering" refers to a process by which objects are created from powders using the mechanism of atomic diffusion. Although atomic diffusion occurs in any material above absolute zero, the process occurs much faster at higher temperatures which is why sintering involves heating a powder. Sintering is different from melting in that the materials never reach a liquid phase during the sintering process. It (SLS) is a powder-based layer-additive manufacturing process generally meant for rapid prototyping and rapid tooling. Laser beams either in continuous or pulse mode are used as a heat source for scanning and joining powders in predetermined sizes and shapes of layers. The geometry of the scanned layers corresponds to the various cross sections of the computer-aided design (CAD) models or (STL) files of the object. After the first layer is scanned, a second layer of loose powder is deposited over it, and the process is repeated from bottom to top until the part is complete. In this process a high power laser beam selectively melts and fuses powdered material spread on a layer. The powder is metered in precise amounts and is spread by a counter-rotating roller on the table. A laser beam is used to fuse the powder within the section boundary through a cross-hatching motion. The table is lowered through a distance corresponding to the layer thickness (usually $0.01 \mathrm{~mm}$ ) before the roller spreads the next layer of powder on the previously built layer. The unsintered powder serves as the support for overhanging portions, if any in the subsequent layers [5] [6].

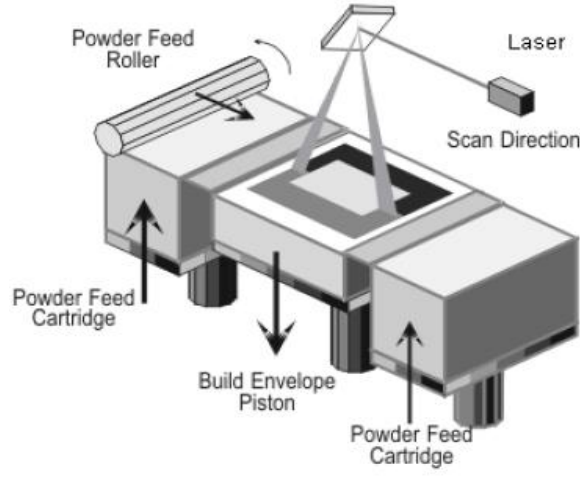

Figure 3. SLS system

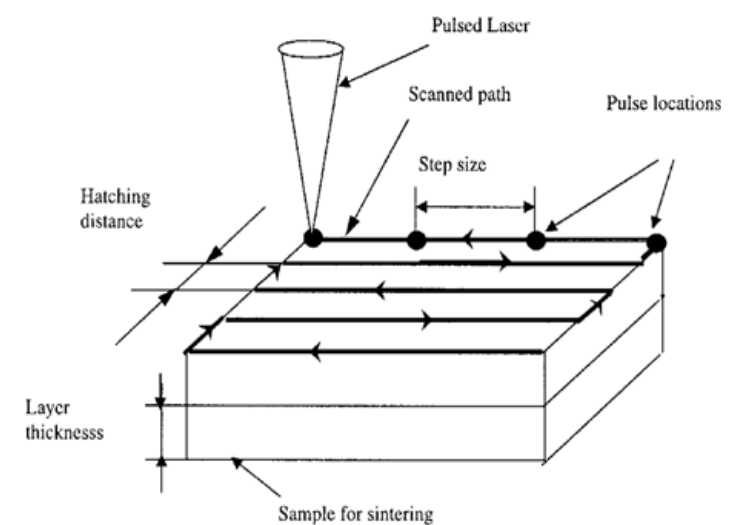

Figure 4. Laser sintering nomenclature [6]

\subsection{Laser}

LASER is the main source to carry out the process which develops energy to sinter the powder particles. The energy source laser is either pulsed or continuous wave laser. Laser power along with the 
scanning speed is one of the important parameter in the laser sintering process as it affects the overall mechanical properties of the produced part for example hardness, strength, porosity. $\mathrm{CO}_{2}$ Laser, Fibre Laser or Nd YAG laser can be used. Now a days. Fibre lasers are becoming most popular due to their high power, excellent control, less maintenance and reliability. The power requirements will depend on the raw material, speed of scanning etc. R. M. Miranda used $8 \mathrm{KW}$ fibre laser to sinter titanium based alloy [7]. K. Murali used pulsed Nd-YAG laser to sinter Iron-Graphite powder mixture and tested the results [6].

\subsection{Powder Feeder}

SLS uses a powder feeder mechanism which lays a powder bed of a predetermined thickness over the base plate on which part is to be built. It is one of the essential component of any SLS based rapid prototyping machine. The layer of powder has to be very accurate and consistent over the complete process assuring the uniformity of the part throughout the geometry. Researchers have used various techniques to deposit a layer for their experiments such as roller arrangements, scrapper blades etc. There are some techniques like 1. Classical deposition 2. Pressure gradient deposition 3. Ultrasound deposition 4. Spread method [8].

\subsection{Enclosed Chamber for controlling the environment}

SLS process involves diffusion of the atoms of one particle into atoms of adjacent particle. The heat energy involved is very high which will be near the melting point of the materials. At this high temperature, there are lot of chances of oxidation of surface which is in contact of the air. To control the oxidation, an inert gas atmosphere is provided. K. Murali [6] used argon gas to drive out the air from reactive zone. Vacuum gives the additional mechanical stability to the part if provided.

\section{MATERIALS FOR SLS}

In SLS, parts can be made out of common engineering thermoplastics such as polyamides, polycarbonates, ABS to metals parts of steel, brass, bronze, titanium. Some of these materials make the SLS process advantageous over the other rapid prototyping techniques. Among these materials, the most common are: wax, paraffin, polymer-metal powders, or various types of steel alloys, polymers, nylon and carbonates. Polycarbonate powders were initially used as starting materials for both experimentation and modelling in the SLS process. For example, a number of systems and metal alloys ( $\mathrm{Fe}-\mathrm{Cu}, \mathrm{Fe}-\mathrm{Sn}$, and $\mathrm{Cu}-\mathrm{Sn}$ ), metals ( $\mathrm{Al}, \mathrm{Cr}, \mathrm{Ti}$, $\mathrm{Fe}$, and $\mathrm{Cu}$ ), ceramics $(\mathrm{Al} 2 \mathrm{O} 3, \mathrm{FeO}, \mathrm{NiO}, \mathrm{ZrO} 2, \mathrm{SiO} 2, \mathrm{CuO})$ and other alloys (bronze, nickel, Inconel 625) were tested for laser sintering [1]. The results demonstrated that any material could be combined with another material with a low melting point and acts as an adhesive. Direct method of sintering doesn't involve binder material while indirect method involved binding of parent material grains with binder coating.

\section{PROCESS PARAMETERS}

The parameters that vary in SLS include powder size, scan speed, powder density, pulse frequency, fill laser power, scan size, scan spacing, part-bed temperature, layer thickness, pulse size, laser power, laser energy, spot size, powder size distribution, ratio of the powders of the mixture [1]. Design of experiment is necessary to find the significant parameters and the effect of those parameters on the physical and mechanical characteristics of the parts.

\section{CHARACTERISTICS OF SLS PRODUCED PARTS}

The measurable properties of sintered parts are yield strength, elongation, Young's modulus, hardness, surface roughness, line width, layer thickness, shrinkage, porosity, wear rate, density, tensile strength, sintering depth and scanning speed [1]. The surface of an SLS part is powdery, like the base material whose particles are fused together without complete melting. The temperature dependence of the SLS process can sometimes result in excess material fusing to the surface of the model, and the thicker layers and variation of the process can result in more $\mathrm{z}$ inaccuracy. SLS parts, because of the supporting powder, sometimes do not need any support. SLS parts can be easily machined compared to SLA and FDM parts. SLS parts are ideally used for form, fit and function and direct manufacturing applications. SLS parts are consistent, stable and durable and provide excellent prototypes and end-use parts for industries and applications that apply demanding and functional testing, giving you the flexibility to modify, optimize and evolve designs on the fly. 


\section{APPLICATIONS}

SLS materials are suited for direct functional applications where robust performance characteristics are required. Chemical resistance to alkalines, hydro carbonates, fuels and solvents, High temperature applications, Wear and abrasion, Flexibility, thin walls, internal/external surface pressures. Applications in the various fields are:

Rapid Manufacturing: Aerospace Hardware, Medical and Healthcare, Electronics, Packaging, Connectors, Homeland Security, Military Hardware Rapid Prototypes, Functional Proof of Concept Prototypes, Design Evaluation Models (Form, Fit \& Function), Product Performance \& Testing, Engineering Design Verification, Wind-Tunnel Test Models.

Tooling and Patterns: Rapid Tooling, Injection Mould Inserts Tooling and Manufacturing Estimating Visual Aid, Investment Casting Patterns Jigs and Fixtures, Foundry Patterns, Sand Casting.

\section{CONCLUSION}

It can be concluded that, among various techniques of rapid prototyping Selective Laser Sintering is the most flexible process that accommodates large variety of materials being processed. Though the technique used is difficult to control and automate as the large number of parameters included, having its superior qualities, it is the most important and useful process for various industrial applications.

\section{REFERENCES}

[1] S. Kumar, (2003). Selective laser sintering: a qualitative and objective approach. JOM, 55(10), 43-47.

[2] S. Singh, A. Sachdeva, and V. S. Sharma, Investigation of Dimensional Accuracy/Mechanical Properties of Part Produced by Selective Laser Sintering, International Journal of Applied Science and Engineering 2012. 10, 1: 59-68.

[3] D. V, Gheorghe, Study of selective laser sintering -A qualitative and objective approach, The Scientific Bulletin of VALAHIA University - MATERIALS and MECHANICS - Nr. 6 (year 9) 2011.

[4] V. K. Singh and N.S. Chauhan, An overview of rapid prototyping technology, IJAET International Journal of Application of Engineering and Technology, vol-2 no.-3, ISSN: 2395-3594.

[5] P.M. Pandey, Rapid prototyping technologies, applications and Part deposition planning.

[6] J.P.Kruth (1991) Material Incress Manufacturing by Rapid Prototyping Technologies, CIRP Annals, Vol. 40, 2, pp 603-614.

[7] Y. Tang, H.T. Loh, Y.S. Wong, J.Y.H. Fuh, L. Lu, X. Wang, Direct laser sintering of a copper-based alloy for creating threedimensional metal parts, Journal of Materials Processing Technology 140 (2003) 368-372.

[8] S.Kolosov, G. Vansteenkiste, N. Boudeau, J.C. Gelin, E. Boillat, Homogeneity aspects in selective laser sintering (SLS). Journal of Materials Processing Technology 177 (2006) 348-351.

[9] K. Murali, A.N. Chatterjee, P. Saha, R. Palai, S. Kumar, S.K. Roy, P.K. Mishra, A. Roy Choudhury, Direct selective laser sintering of iron-graphite powder mixture, Journal of Materials Processing Technology 136 (2003) 179-185.

[10] R.M. Miranda, G. Lopes, L. Quintino, J.P. Rodrigues, S. Williams, Rapid prototyping with high power fiber lasers, Materials and Design 29 (2008) 2072-2075.

[11] A.N. Chatterjee, Sanjay Kumar, P. Saha, P.K. Mishra, A. Roy Choudhury, An experimental design approach to selective laser sintering of low carbon steel, Journal of Materials Processing Technology 136 (2003) 151-157.

[12] P. Bai, W. Wang, Selective laser sintering mechanism of polymer-coated molybdenum powder, Trans. Nonferrous Mct. Soc. China 17(2007) 543-547. 